\title{
Challenges in Identifying Factors Which Determine the Placement of Children in Care? An International Review
}

\author{
Kish Bhatti-Sinclair, University of Chichester* \\ Charles Sutcliffe, University of Reading**
}

27 October 2012

Keywords: Placement decision; Foster care; Out-of-home care; Modelling.

We wish to thank Patrick O'Leary for his very helpful comments on an earlier draft of this paper.

* Kish Bhatti-Sinclair. Head of Qualifying Social Work Programmes, Department of Childhood, Social Work and Social Care University of Chichester Bishop Otter Campus Chichester PO19 6PE, UK. Tel: +44(0)1243-816349, email K.Bhatti-Sinclair@,chi.ac.uk Corresponding author

** Charles Sutcliffe. The ICMA Centre, University of Reading, PO Box 242, Reading RG6 6BA, UK, tel +44 (0)118-378-6117, email c.m.s.sutcliffe@rdg.ac.uk 


\title{
Challenges in Identifying Factors Which Determine the
}

\section{Placement of Children in Care? An International Review}

\begin{abstract}
Placing a child in out-of-home care is one of the most important decisions made by professionals in the child care system, with substantial social, psychological, educational, medical and economic consequences. This paper considers the challenges and difficulties of building statistical models of this decision by reviewing the available international evidence. Despite the large number of empirical investigations over a fifty year period, a consensus on the variables associated with this decision is hard to identify. In addition, the individual models have low explanatory and predictive power and should not be relied on to make placement decisions. A number of reasons for this poor performance are offered, and some ways forwards suggested. This paper also aims to facilitate the emergence of a coherent and integrated international literature from the disconnected and fragmented empirical studies. Rather than one placement problem, there are many slightly different problems, and therefore it is expected that a number of related sub-literatures will emerge, each concentrating on a particular definition of the placement problem.
\end{abstract}




\section{Challenges in Identifying Factors Which Determine the Placement of Children in Care? An International Review}

\section{Introduction}

This paper reviews previous research which has used statistical analysis to identify the variables associated with the decision to place a child in care. It analyses 63 empirical studies of children placed in out-of-home care, the difficulties and challenges involved in building and comparing such research, and the extent to which these studies have been successful. The decision on whether or not to place a child can have important social, psychological, educational, medical and economic implications. Equally, placing children in care (rather than leaving them at home) can lead to behavioural problems. Rosenthal, Motz, Edmonson and Groze (1991), Poertner, Bussey and Fluke (1999) and Hobbs, Hobbs and Wynne (1999) have documented the abuse and neglect of 6,878 children in out-of-home placements in Colorado, USA, Illinois, USA and Leeds, UK, respectively. As well as personal costs, out-of-home placements can add to public sector spending; for example, Barth, Lee, Wildfire and Guo (2006a) estimated the average cost of keeping a child in foster care in North Carolina, USA, at $\$ 16,000$ per year in 1995 , equivalent to $\$ 24,000$ in 2011 . In 2011 there were 400,540 children in care in the USA (Children's Bureau, 2012). Therefore, the total costs of placement are formidable, and of interest to policy makers responsible for welfare funding.

Placement decision models entail a number of important challenges and difficulties, and an international review of the available studies should be helpful in providing a summary of the current state of knowledge on the extent to which the factors determining placement can be identified. Placement researchers usually reference only a few previous studies, and this has discouraged the development of national and international comparisons. The aim of this paper is to unify the disconnected and fragmented literature, identify the challenges and difficulties facing researchers, and encourage the emergence of an accepted set of important factors for each type of placement decision.

Section 2 describes the international literature on the placement decision, and section 3 considers various challenges and difficulties in modelling this decision. Section 4 summarises the different definitions of the placement problem used in previous research, while section 5 attempts to identify the factors associated with different definitions of out-of-home placement. Section 6 describes various 
aspects of the data used in these studies and how these can complicate comparisons between studies. Finally, the conclusions appear in section 7.

\section{Literature}

Three previous papers have reviewed the literature on placement decisions (Jones, 1993, DePanfilis and Scannapieco, 1994 and Lindsey, 1992a), but these are almost 20 years old, and only use evidence from the USA. Sixty further studies have been published in subsequent years, and together with the earlier non-US studies, form a substantial body of unreviewed papers which are included in the present study.

A variety of search engines (Web of Knowledge, International Bibliography of the Social Sciences, Google) were used to identify research published in English which used statistical analysis to identify the factors leading to children being placed in out-of-home care. Studies of any country at any date were included, as were studies at both the national and sub-national levels. References within the identified papers were also examined, and this process led to the identification of 96 studies. Eight studies with no control group, eight focusing on the views of child care workers, and 17 where the placement decision was the choice between different types of out-of-home care were excluded. Therefore, the final list of research papers comprised 63 studies of the choice between leaving a child at home and placing them in some form of out-of-home care.

Academic interest in the placement decision began approximately fifty years ago in the USA (e.g. Briar, 1963; and Boehm, 1962). Of the 63 empirical studies published in English since then, 45 have used American data, and the remainder are from Canada (5), Denmark (4), Sweden (3), UK (3), Israel (1), the Netherlands (1) and Australia (1), see Table 1. The international spread of these studies is very uneven, with $71 \%$ relating to the USA. Thirty six of the 63 studies were conducted at the sub-national level (regions, states, counties, cities, etc.), and the remaining 27 at the national level. The number of placement studies has increased over time, suggesting that interest in the placement decision is growing. There was one study in the 1970s, seven in the 1980s, 15 in the 1990s, and 28 in the 2000s. For 2010 and 2011 there were 12 studies, i.e. a rate of 60 per decade. 


\section{Modelling Challenges}

Every child and family situation is unique, and this complexity makes statistical modelling of the placement decision difficult. Individual needs can lead to substantial unexplained variation in placement decisions, making it difficult to find powerful independent variables. Furthermore, studies have been conducted at different times and in different countries, adding a further level of complexity to comparisons ${ }^{1}$. However, most of the empirical studies quantify the decision making of many child protection workers, across a large number of different situations, resulting in the measurement of the average relationship between the independent variables considered and the placement decision. Therefore idiosyncratic differences between cases should tend to average out over large samples. The extent to which this permits successful model building is an empirical question considered below.

The criteria for placing children vary across local authorities, child protection teams, and individual professionals. Using a common set of case studies to control for variations in the child and their circumstances, a number of studies have found substantial disagreement between individual child protection workers when recommending whether or not to place a particular child in care (Schuerman, Rossi and Budde, 1999; Rapp, 1982; Phillips, Shyne, Sherman and Harding, 1971; Kang and Poertner, 2006). This may be because professionals have significant differences in the importance they attach to the same piece of information (Britner and Mossler, 2002). Such inconsistencies in practice raise questions about the extent to which placement decisions are based on a systematic analysis and established knowledge, and make it difficult to build statistical models of the placement decision.

All the researchers used a statistical technique to analyse the data. Forty one previous studies used logistic regression (or logit analysis), while discriminant analysis was used in eight studies, with one study using probit analysis and one using an artificial neural network. In addition, as shown in Table 1, a range of other techniques were deployed - multiple linear regression (4), chi-squared tests (1), log linear analysis (1), descriptive statistics (2), odds ratios (1), survival analysis (1), hazard models (2) and aggregate risk scores (1). These results reveal that logistic regression is the technique of choice for tackling the placement problem. However, discriminant analysis, probit analysis and artificial neural networks are valid alternatives to logistic regression. Some new classification techniques are

1 (Gilbert, Parton and Skivenes (2011) contains a description of the child protection systems in all the countries included in this paper, apart from Australia and Israel. 
also available, but have yet to be applied to the placement problem, e.g. random forests (Breiman, 2001). Besides raising the possibility that the conclusions are influenced by the chosen statistical technique, some of the previously used techniques are unsuitable for the placement problem, e.g. multiple linear regression, making the findings of such studies unreliable ${ }^{2}$.

\section{Definition of the Placement Problem}

Despite the use of different definitions of the placement decision in previous studies, it has often been seen as a single problem when, in fact, it consists of many slightly different classification problems. Table 1 presents an overview of the literature with evidence from eight counties, highlighting the importance of carefully defining the particular placement decision under consideration. (Ten studies present results for two or more samples, and so Table 1 has 75 entries.) The observations for each study are divided into groups A and B in columns 3 and 4 of Table 1; (A) the placed group, and (B) the children not placed (the control group). These give the definitions of the two groups involved in the two-way classification problem, while columns 5 and 6 contain the numbers of children in each group. (The definitions of the two groups used in Table 1 rely on the definitions used by the studies, and in some cases the precise definitions are unclear.) Table 1 shows that three different definitions have been used for the "placed" group of children (Group A); i.e. out-of-home care (61), foster care (12), and out-of-home living (2).

The definitions of the "non-placed" children (Group B) are much wider, and have been classified in Table 1 as follows: general population (19), at risk of placement (14), abused or neglected (11), child maltreatment (9), service at home (6), sexual abuse (3), status offence (2), mental health problems (2), control sample (1), exposed to violence (1), suspected child abuse (1), delinquency (1) substantiated maltreatment (1), sibling maltreatment death (1), sexually abused black girls (1), referred by the court (1) and self-reported maltreatment (1).

Different definitions of the "placed" and "non-placed" children will result in different discriminating variables; for example, the differences between apples and oranges are quite different from the

${ }^{2}$ A few authors have used multiple linear regression to estimate the factors associated with the placement decision, but there are powerful objections to this approach (Brooks, 2008). Because the dependent variable is a probability, it must lie in the zero-one range. However multiple linear regression can easily predict negative probabilities, or probabilities above one, which are impossible. 
differences between apples and plums. Such differences between studies make it difficult to draw general conclusions on what factors are important, and the magnitude of the association of these factors with the placement decision. In essence, many different placement decisions have been studied. For example, if there are three alternatives for group A, and 17 alternatives for group B, there are potentially 51 different placement problems.

While accepting there are many different placement problems, 43 existing studies can be allocated to five main groups. The remaining 20 studies were of some particular sub-group, e.g. Korean Americans, Chinese Americans, American Indians, children exposed to cocaine, violence or sexual abuse, referred by the court, living in urban/non-urban areas, experienced an inpatient psychiatric episode or had a sibling die from maltreatment, referred for a status offence, delinquency, substantiated maltreatment or suspected child abuse. These studies are heterogeneous with too few of each type to draw more general conclusions, and so have been excluded from this review.

\section{Factors Leading to Out-of-Home Placement}

Column B of Table 1 identifies the control group for the remaining 43 studies as falling into one of five groups - general population (13), abused and neglected (9), children receiving service at home (6), maltreated children (7) and children at risk of placement (8). Each of these groups represents a slightly different definition of the placement problem, and so each group will be examined separately to look for a set of common independent variables associated with the placement decision.

General Population. Comparisons of the general population with placed children provide one of the sharpest comparisons, and therefore increase the chances of finding significant differences between the two groups. The13 studies under question cover four countries - Denmark (4), Sweden (3), USA (3) and the UK (3). In every study single parent families were more likely to have a child placed. The placement risk also increased in many studies if the mother was unemployed, received state benefits, had only a basic education or had a criminal conviction. Other factors associated with an increased risk of placement included low family income, overcrowded housing, non-immigrant parents, parental mental health problems, living in council or rented housing, a teenage mother, a low birth weight, a birth abnormality, frequent residential moves, and having parents who were themselves in care. 
The next four sections consider children brought to the attention of the child protection system. For these children, distinguishing between the placed and non-placed is a greater challenge than when the non-selected group is the general population, as both sets of children already possess the common characteristic of receiving attention from the child care system. However, this is also the more relevant question for child protection workers because this is closer to the choice they actually have to make.

Abused and Neglected Children. Parental substance abuse and families with a history of involvement with child care services were the most common factors for abused and neglected children. Parental mental disorder, poverty, and families with infant children were also found by three studies.

Children Receiving Service at Home. Five of the studies identified poverty, while three specified a family history of involvement with child care services and the child being an infant as associated with placement. Other factors include single parent families, mental illness, being African-American and child behavioural difficulties.

Maltreated Children. The three most common factors were being African-American, parental substance abuse and emotional abuse. Being an infant, parental mental health problems and poverty were also found to contribute, but to a lesser extent.

Children at Risk of Placement. Five of these studies used unconventional independent variables for children seen as at risk of placement, e.g. indices constructed from a quality of life questionnaire. or the Nijmegen child-rearing situation questionnaire. Of the remaining three studies, two identified being a single parent family as important.

This broad brush summary of the findings of previous studies reveals that the important independent variables differ from one group of studies to another, supporting the view that different placement problems have different discriminating variables. Therefore, any particular piece of research on placement decision-making relates to only a small number of these studies. However, within any one group of studies there is only modest agreement on the powerful independent variables. The one exception is those studies using the general population, which all found that being a single parent 
family increased the risk of placement. As well as being clear about the definition of the placement problem they are studying, researchers also need to consider the issues concerning the data discussed in the next section.

\section{The Data Used in Placement Studies}

It is difficult to divide the sources of data on children into discrete categories, but some general observations are possible. The data ranges from specially conducted large scale surveys to research studies relying on a small number of case studies. Administrative data already held on children living in a particular area has also been analysed, or used to select cases for interview. In some cases national administrative data were used to perform large scale studies. Problems arising from the data, and its use in model building, and in interpreting and comparing studies is considered below.

Subjective Variables. The administrative and survey data commonly includes just facts, such as age or gender, while the studies using casework information also include highly subjective variables (e.g. psychological and behavioural indices) generated by the child protection professionals or the researchers. Since the measurement and definition of these subjective variables is arbitrary and differs from study to study, it is hard to interpret the magnitude of their effect on the placement decision, or to compare the results of different studies.

Sample Size. The sample sizes used in previous studies vary considerably. Studies using administrative or survey data can be very large, e.g. Lindsey (1991) studied 350,812 children placed in foster care, compared with 466,498 children who received service at home (see Table 1 for the wide range of sample sizes). In contrast, studies based on case work data generally have much smaller samples, e.g. Pellegrin and Wagner (1990) studied 18 sexually abused children placed in out-of-home care, and 25 sexually abused children not placed in care. Due to differences in statistical power stemming from variations in sample size, variables that are significant in a large sample study may be insignificant in a small sample study, complicating any comparison of the conclusions from different studies.

Many Explanatory Variables. A great many variables are thought to be relevant to placement decisions, and some empirical studies have considered over a hundred different variables. This raises 
the difficulty of identifying and measuring all these variables, with the problem of multicollinearity affecting the estimation of their individual effects. In addition, since there is a very large number of potential independent variables, and the data available to researchers differs, studies have investigated the effects of different sets of variables on the placement decision. In consequence, even if two researchers have studied the same placement decision, different sets of independent variables will probably have been used, making it difficult to compare their results.

Omitted Variables. While there is a large number of potential independent variables, the availability of data constrains the factors that can be examined in an empirical analysis. So it is possible that a powerful independent variable has been omitted from the analysis, leading to omitted variable bias. This causes the estimated coefficients for the included independent variables to be biased, unless the independent variable has zero correlation with the omitted variable. In addition, omitted variable bias inflates the estimated standard errors for all the estimated coefficients, reducing their apparent significance.

The possibility of important variables being omitted can be investigated by computing a measure of the explanatory power of the fitted models, i.e. what proportion of the total variation in the dependent variable is explained by the independent variables in the model $\left(R^{2}\right)$. Only 18 of the 63 studies provided a measure of the explanatory power of their model, and these $R^{2}$ values are low, averaging under $23 \%$, i.e. the models explain only $23 \%$ of the variation in the placement decision ${ }^{3}$. Substantial unexplained variation is expected due to the exercise of judgment by the decision-makers; but the very large unexplained variation in the dependent variable should result in research into identifying missing independent variables that are quantifiable and increase the explanatory power of the models.

There are a few variables whose omission appears not to be a problem. For example, Rossi, Schuerman and Budde (1999) found that the characteristics of the case worker do not affect the placement decision (e.g. their background and work experience), and so excluding this variable from the analysis does not alter the results. Another concern is highlighted by Britner and Mossler (2002), who show that there are differences between professional groups (social and mental health workers, judges and guardians, special advisors) in the importance they attach to various pieces of information.

\footnotetext{
${ }^{3}$ Low $\mathrm{R}^{2}$ values are common in social science research, particularly in cross-section studies.
} 
However, since the research is of the decision-making process in its entirety, this omission is also unimportant.

Reason for Placement. It is possible that what appears to be a homogenous placement problem, e.g. out-of-home care versus the general population, actually comprises a number of separate placement problems. It may be that the characteristics of parents/carer and children vary with the primary reason for placement. If the child is placed due to the short-term serious physical illness of the primary carer, or because of some short-term family emergency, the characteristics of the parents/carer and children may differ from those where the placement is for drug addiction. In some previous studies the decision-makers have specified the main reason for the placement, while in other cases this is unknown. When using survey data the primary reason for placement is often unspecified, making it impossible to disaggregate the sample according to the primary reason for placement. However, it is possible to use the child's age as a proxy for the reason for placement. Delfabbro, Barber and Cooper (2002) argue that children taken into out-of-home care fall into two distinct groups - young children whose parents have problems, and adolescents who themselves have problems, and a study of 235 children taken into care in South Australia found evidence of two such distinct clusters. This suggests that studies that do not include the primary reason for placement as an independent variable should analyse children and adolescents separately. This has been done by six recent studies (Elmund, Lindblad, Vinnerljung and Hjern, 2007; Knoke, Goodman, Leslie and Trocmé, 2007; Franzen, Vinnerljung and Hjern, 2008: Vinnerljung, Franzen, Gustafsson and Johansson, 2008, Andersen and Fallesen, 2010 and Ejrnaes, Ejrnaes and Frederiksen, 2011).

Constraints Omitted. It is possible that placement decisions are influenced by capacity constraints on the supply of various types of service; for example, a child is not placed in care because some capacity limit has been reached. This issue has not been considered in placement studies, probably because of difficulties in determining the service capacity available at the time and place of each placement decision. Rapp (1982), showed that the availability of family support services has little effect on the foster care placement decision, while Duncan and Argys (2007) found that increasing the payment to US foster parents leads to more children being placed in foster care, presumably because the supply of foster care places is increased. Berger (2006) reached a similar conclusion. Capacity constraints could be an important factor in the placement of some children, even though at different places or 
times within the sample there is no lack of capacity. With such constraints omitted, when averaged out over the sample area and over time, the results reflect the effects of the average capacity constraint on placement decisions. However, the models do not specifically quantify these capacity effects, and so they are conflated into the coefficients of the model's independent variables.

Neighbourhood Effects. Andersen (2010) found that out-of-home placement rates for areas of Denmark vary with the level of local preventative measures, school class sizes, local cultural and sport expenditure, urbanization, rented housing, immigrants and single parent families. Lery (2009) also found that out-of-home placement rates in Alameda County, California vary with neighbourhood factors such as residential instability and impoverishment. Variations in foster care placement rates between 579 zip codes in California were studied by Freisthler, Gruenwald, Remer, Lery and Needell (2007). They discovered that placement rates differed with the number of alcohol outlets, average household size, median household income, median child age and the proportion of black Americans. Curtis and Alexander (2010) looked for neighbourhood effects on the placement of black children in Franklin County, California, but failed to find any significant effects.

In Finland the annual rate of change in the proportion of children with out-of-home placements varies with regional differences in sales of alcohol, the divorce rate and the unemployment rate (Hiilamo, 2009). Some of the regional and neighbourhood variables (e.g. unemployment, alcohol abuse, single parent family, rented housing) appear in the individual case data, and so some of their effects on individual families are picked up at the case level, although not their indirect neighbourhood effects. These regional and neighbourhood factors vary from case to case, and if these variables are omitted from the analysis the model coefficients reflect their average indirect effects (although their effects are not specifically quantified). Including neighbourhood effects into studies of the placement decision requires data on the spatial location of each child, as well as the characteristics of each neighbourhood. Data on the location of children may be unavailable due to confidentiality policies and procedures, making it impossible to determine which neighbourhood data to use.

Time Series Effects. As well as neighbourhood (cross-sectional) effects, there may be time series effects. For example, Catalano, Lind, Rosenblatt and Attkisson (1999) showed that changes in the number of children in foster care each month vary with changes in the monthly state unemployment 
rate in California. Such time series effects imply that the coefficients of a placement model may change over time, although it is also possible that the unemployment variable in a model using observations on individual children picks up some or all of these state-wide time series effects.

\section{Conclusions}

The placement decision is one of the most important decisions made by child protection workers, and has attracted a considerable number of research studies (96). The main aim of the models estimated in these studies is to understand the factors involved in making and predicting placement decisions. This paper has set out the challenges rather than definitive answers to the difficulties of analysing data to inform policy and practice. It has also collected together the fragmented literature, and demonstrated that research on making the placement decision is international.

Rather than one placement problem, there are many; and for a particular placement problem, the results of different studies need to be interpreted with care, as there are substantial differences between studies. Despite the large number of empirical investigations, a consensus on the variables associated with this decision is hard to identify. This is partly due to variations between studies in the definition of the placement decision, the type, identity and measurement of the variables, the sample size, family circumstances, the way care workers make placement decisions, the time period and the country studied. In addition, for some studies the definition of the placed and non-placed groups are unclear. These differences and definitional issues make it difficult to make comparisons. Modelling and predicting the placement decision is also challenging because every placement decision is unique, involving a multitude of independent variables, many of which are hard to quantify. There is also the issue that child care workers may make idiosyncratic decisions which do not conform with a set of commonly held professional criteria.

In consequence, the success of these studies has been very limited, and the classification of children using these models should not be relied on to make placement decisions for three reasons. First, while the models have some highly significant estimated coefficients, their $R^{2}$ values are disappointingly low and the models have poor predictive power. Second, these models rely on the decisions actually made by child protection workers, which may not be optimal. Third, there is an absence of a generally accepted set of key variables which are strongly associated with the placement decision. 
Further child-centered research is needed to inform professionals seeking to make informed decisions within specific practice contexts. Such models require high $R^{2}$ values based on an accepted set of key variables, and clear definitions based on discriminating variables aligned with the experience of children in care.

Future research could replicate placement studies with data for a later period, with all other aspects of the analysis held constant, permitting an investigation of the temporal stability of the estimated coefficients. The extent to which placement decision-making varies between regions may be analysed by disaggregating a large national dataset. Access to data held by related welfare organizations (for example, those holding health data) would enable the analysis of new independent variables which may improve the performance of the models. Researchers could also include neighbourhood variables, out-of-home care capacity constraints, and the reason for placement as independent variables. Finally, different statistical techniques could be applied.

It is possible that, despite such efforts, satisfactory models of the placement decision cannot be developed. This may be either because the problem is too complex, with its focus on individual needs; or because child care workers make inconsistent decisions which no model is capable of explaining. 


\section{References}

Andersen, S.H. (2010) A Good Place to Live? On Municipality Characteristics and Children's Placement Risk, Social Services Review, vol. 84, no. 2, June, pp. 201-224.

Andersen, S.H. and Fallesen, P. (2010) A Question of Class: On the Heterogeneous Relationship Between Background Characteristics and a Child's Placement Risk, Children and Youth Services Review, vol. 32, no. 6, June, pp. 783-789.

Barth, R.P., Lee, C.K., Wildfire, J. and Guo, S. (2006a) A Comparison of the Governmental Costs of LongTerm Foster Care and Adoption, Social Services Review, vol. 80, no. 1. March, pp. 127-158.

Barth, R.P., Wildfire, J. and Green, R.L. (2006b) Placement into Foster Care and the Interplay of Urbanicity, Child Behaviour Problems and Poverty, American Journal of Orthopsychiatry, vol. 76, no. 3, July, pp. 358-366.

Bebbington, A.C. and Miles, J.B. (1988) A Need Indicator of In Care Services for Children, Personal Social Services Research Unit, Discussion Paper 574, University of Kent.

Bebbington, A. and Miles, J. (1989) The Background of Children Who Enter Local Authority Care, British Journal of Social Work, vol. 19, no. 1, pp. 349-368.

Berger, L.M. (2006) Children Living Out-of-Home: Effects of Family and Environmental Characteristics, Children and Youth Services Review, vol. 28, no. 2, February, pp. 158-179.

Berger, L.M. and Waldfogel, J. (2004) Out-of-Home Placement of Children and Economic Factors: An Empirical Analysis, Review of Economics of the Household, vol. 2, no. 4, December, pp. 387-411.

Boehm, B. (1962) An Assessment of Family Adequacy in Protective Cases, Child Welfare, vol. 41, January, pp. 10-16.

Briar, S. (1963) Clinical Judgment in Foster Care Placement, Child Welfare, vol. 42, April, pp. 161-169.

Breiman, L. (2001) Random Forests, Machine Learning, vol. 45, no. 1, October, pp. 5-32.

Britner, P.A. and Mossler, D.G. (2002) Professionals' Decision making About Out-of-Home Placements Following Instances of Child Abuse, Child Abuse and Neglect, vol, 26, no. 4, April, pp. 317-332.

Brooks, C. (2008) Introductory Econometrics for Finance, Cambridge University Press, Second edition.

Carter, V.B. (2009) Prediction of Placement into Out-of-Home Care for American Indian/Alaskan Natives Compared to Non-Indians, Children and Youth Services Review, vol. 31, no. 8, August, pp. 840-846.

Carter, V.B. (2010) Factors Predicting Placement of Urban American Indian/Alaskan Natives into Out-ofHome Care, Children and Youth Services Review, vol. 32, no. 5, May, pp. 657-663.

Catalano, R.A., Lind, S.L., Rosenblatt, A.B. and Attkisson, C.C. (1999) American Journal of Public Health, vol. 89 , no. 6 , June, pp. 851-855.

Chang, J., Rhee, S. and Weaver, D. (2006) Characteristics of Child Abuse in Immigrant Korean Families and Correlates of Placement Decisions, Child Abuse and Neglect, vol. 30, no. 8, August, pp. 881-891.

Children's Bureau (2012) AFCARS Report \#19, US Department of Health and Human Services, Administration on Children, Youth and Families, July. http://www.acf.hhs.gov/programs/cb/resource/afcars-report-19

Curtis, C.M. and Alexander, R. (2010) Correlates of African American Children In and Out of Their Families, Families in Society, vol. 91, no. 1, January-March, pp. 85-90.

Dalgleish, L.I. and Drew, E.C. (1989) The Relationship of Child Abuse Indicators to the Assessment of Perceived Risk and to the Court's Decision to Separate, Child Abuse and Neglect, vol. 13, no. 4, pp. 491-506.

Damashek, A. and Bonner, B.L. (2010) Factors Related to Sibling Removal After a Child Maltreatment Fatality, Child Abuse and Neglect, vol. 34, no. 8, August, pp. 563-569.

Davidson-Arad, B., Englechin-Segal, D., Wozner, Y. and Arieli, R. (2006) Social Workers' Decisions on Removal: Predictions from their Initial Perceptions of the Child's Features, Parents' Features and Child's Quality of Life, Journal of Social Service Research, vol. 31, no. 4, pp. 1-23.

De Kemp, R.A.T., Veerman, J.W. and Brink, L.T.T. (2003) The Assessment of Imminence of Risk of Placement: Lessons from a Families First Program in the Netherlands, Children and Youth Services Review, vol. 25, no. 3, pp. 251-270.

DePanfilis, D. and Scannapieco, M. (1994) Assessing the Safety of Children at Risk of Maltreatment: DecisionMaking Models, Child Welfare, vol. 73, no. 3, May-June, pp. 229-245.

Delfabbro, P.H., Barber, J.G. ad Cooper, L. (2002) Children Entering Out-of-Home Care in South Australia: Baseline Analyses for a 3-Year Longitudinal Study, Children and Youth Services Review, vol. 24, no. 12, December, pp. 917-932. 
Duncan, B. and Argys, L. (2007) Economic Incentives and Foster Care Placement, Southern Economic Journal, vol. 74, no. 1. July, pp. 114-142.

Ejrnæs, M, Ejrnæs, M, and Frederiksen, S. (2011) Risk Factors of Entry in Out-of-Home Care: An Empirical Study of Danish Birth Cohorts, 1981-2003, Child Indicators Research, vol. 4, no. 1, January, pp. 2144.

Elmund, A., Lindblad, F., Vinnerljung, B. and Hjern, A. (2007) Intercountry Adoptees in Out-of-Home Care: A National Cohort Study, Acta Paediatrica, vol. 96, no. 3, March, pp. 437-442.

English, D.J., Edleson, J.L. and Herrick, M.E. (2005) Domestic Violence in One State's Child Protective Caseload: A Study of Differential Case Dispositions and Outcomes, Children and Youth Services Review, vol. 27, no. 11, November, pp. 1183-1201.

Farmer, E.M.Z., Mustillo, S., Burns, B.J. and Holden, E.W. (2008) Use and Predictors of Out-of-Home Placements Within Systems of Care, Journal of Emotional and Behavioural Disorders, vol. 16, no. 1, March, pp. 5-14.

Fluke, J.D., Chabot, M., Fallon, B., MacLaurin, B. and Blackstock, C. (2010) Placement Decisions and Disparities Among Aboriginal Groups: An Application of the Decision Making Ecology Through Multi-Level Analysis, Child Abuse and Neglect, vol. 34, no. 1, January, pp. 57-69.

Franzen, E., Vinnerljung, B. and Hjern, A. (2008) The Epidemiology of Out-of-Home Care for Children and Youth: A National Cohort Study, British Journal of Social Work, vol. 38, no. 6, December, pp. 10431059.

Freisthaler, B., Gruenwald, P.J., Remer, L.G., Lery, B. and Needell, B. (2007) Exploring the Spatial Dynamics of Alcohol Outlets and Child Protective Services Referrals, Substantiations and Foster Care Entries, Child Maltreatment, vol. 12, no. 2, May, pp. 114-124.

Gilbert, N., Parton, N. and Skivenes, M. (eds) (2011) Child Protection Systems: International Trends and Orientations, Oxford University Press.

Glisson, C. and Green, P. (2006) The Role of Specialty Mental Health Care in Predicting Child Welfare and Juvenile Justice Out-of-Home Placements, Research on Social Work Practice, vol. 16, no. 5, September, pp. 480-490.

Goerge, R.M. and Lee, B.J. (2005) The Entry of Children from the Welfare System into Foster Care: Differences by Race. In Race Matters in Child Welfare edited by D.M. Derezotes, J. Poertner and M.F. Testa, Child Welfare League of America, pp. 173-185.

Harpaz-Rotem, I., Berkowitz, S., Marans, S. Murphy, R.A. and Rosenheck, R.A. (2008) Out-of-Home Placement of Children Exposed to Violence, Children and Society, vol. 22, no. 1, January, pp. 29-40.

Harris, G., Tittle, G. and Poertner, J. (2005) Factors that Predict the Decision to Place a Child in Substitute Care. In Race Matters in Child Welfare edited by D.M. Derezotes, J. Poertner and M.F. Testa, Child Welfare League of America, pp. 163-172.

Hearn, J.L. (2010) Family Preservation in Families' Ecological Systems: Factors that Predict Out-of-Home Placement and Maltreatment for Service Recipients in Richmond City, Ph.D. thesis, Virginia Commonwealth University, Richmond, Virginia.

Hestbæk, A.D. (1999) Social Background and Placement Course - The Case of Denmark, International Journal of Social Welfare, vol. 8, no. 4, October, pp. 267-276.

Hiilamo, H. (2009) What Could Explain the Dramatic Rise in Out-of-Home Placement in Finland in the 1990s and Early 2000s?, Children and Youth Services Review, vol. 31, no. 2, February, pp. 177-184.

Hill, R.B. (2005) The Role of Race in Foster Care Placements. In Race Matters in Child Welfare edited by D.M. Derezotes, J. Poertner and M.F. Testa, Child Welfare League of America, pp. 187-200.

Hobbs, G.F., Hobbs, C.J. and Wynne, J.M. (1999) Abuse of Children in Foster and Residential Care, Child Abuse and Neglect, vol. 23, no. 12, December, pp. 1239-1252.

Horowitz, S.M., Hurlburt, M.S., Cohen, S.D. and Zhang, J. (2011) Predictors of Placement for Children Who Initially Remained in Their Homes After an Investigation for Abuse or Neglect, Child Abuse and Neglect, vol. 35, no. 3, March, pp. 188-198.

Hunter, W.M., Coulter, M.L., Runyan, D.K. and Everson, M.D. (1990) Determinants of Placement for Sexually Abused Children, Child Abuse and Neglect, vol. 14, no. 3, pp. 407-417.

Jaudes, P.K. and Morris, M. (1990) Child Sexual Abuse: Who Goes Home?, Child Abuse and Neglect, vol. 14, no. 1, pp. 61-68.

Jones, M.A. (1985) A Second Chance for Families: Five Years Later, Child Welfare League of America, New 
York.

Jones, L.J. (1993) Decision Making in Child Welfare: A Critical Review of the Literature, Child and Adolescent Work, vol. 10, no. 3, June, pp. 241-262.

Kang, H.A. and Poertner, J. (2006) Inter-Rater Reliability of the Illinois Structured Decision Support Protocol, Child Abuse and Neglect, vol. 30, no. 6, June, pp. 679-689.

Katz, M.H., Hampton, R.L., Newberger, E.H., Bowles, R.T. and Snyder, J.C. (1986) Returning Children Home: Clinical Decision Making in Cases of Child Abuse and Neglect, American Journal of Orthopsychiatry, vol. 56, no. 2, April, pp. 253-262.

Knoke, D., Goodman, D., Leslie, B. and Trocmé, N. (2007) Differences in the Factors Associated With Out-ofHome Placement for Children and Youth, Canadian Journal of Social Work, vol. 9, no. 1, 2007, pp. 26-46.

Knott, T. and Donovan, K. (2010) Disproportionate Representation of African-American Children in Foster Care: Secondary Analysis of the National Child Abuse and Neglect Data System, 2005, Children and Youth Services Review, vol. 32, no. 5, May, pp. 679-684.

Lau, A., McCabe, K.M., Yeh, M., Garland, A.F., Hough, R.L. and Landsverk, J.A. (2003) Race-Ethnicity and Rates of Self-Reported Maltreatment Among High Risk Youth in Public Sectors of Care, Child Maltreatment, vol. 8, no. 3, August, pp. 183-194.

Lavergne, C., Damant, D., Clement, M., Bourassa, C., Lessard, G. and Turcotte, P. (2011) Key Decisions in Child Protection Services in Cases of Domestic Violence: Maintaining Services and Out-of-Home Placement, Child and Family Social Work, vol. 16, no. 3, August, pp. 353-363.

Leifer, M., Shapiro, J. and Kassem, L. (1993) The Impact of Maternal History and Behaviour Upon Foster Placement and Adjustment in Sexually Abused Girls, Child Abuse and Neglect, vol. 17, no. 6, pp. 755766.

Lery, B. (2009) Neighborhood Structure and Foster Care Entry Risk: The Role of Spatial Scale in Defining Neighborhoods, Children and Youth Services Review, vol. 31, no. 3, March, pp. 331-337.

Leschied, A.W., Chiodo, D., Whitehead, P.C., Hurley, D. and Marshal, L. (2003) The Empirical Basis of Risk Assessment in Child Welfare: The Accuracy of Risk Assessment and Clinical Judgement, Child Welfare, vol. 82, no. 5, September-October, pp. 527-540.

Lightfoot, E., Hill, K. and LaLiberte, T. (2011) Prevalence of Children with Disabilities in the Child Welfare System and Out-of-Home Placement: An Examination of Administrative Records, Children and Youth Services Review, vol. 33, no. 11, pp. 2069-2075.

Lindsey, D. (1991) Factors Affecting the Foster Care Placement Decision: An Analysis of Natural Survey Data, American Journal of Orthopsychiatry, vol. 62, no. 2, April, pp. 272-281.

Lindsey, D. (1992a) Reliability of the Foster Care Placement Decision: A Review, Research on Social Work Practice, vol. 2, no. 1, January, pp. 65-80.

Lindsey, D. (1992b) Adequacy of Income and the Foster Care Placement Decision: Using an Odds Ratio Approach to Examine Client Variables, Social Work Research and Abstracts, vol. 28, no.3, September, pp. 29-36.

McDonald, T.P., Poertner, J. and Harris, G. (2001) Predicting Placement in Foster Care: A Comparison of Logistic Regression and Neural Network Analysis, Journal of Social Service Research, vol. 28, no. 2, pp. 1-20.

Needell, B. and Barth, R.P. (1998) Infants Entering Foster Care Compared to Other Infants Using Birth Status Indicators, Child Abuse and Neglect, vol. 22, no. 12, December, pp. 1179-1187.

Needell, B., Brookhart, M.A. and Lee, S. (2003) Black Children and Foster Care Placement in California, Children and Youth Services Review, vol. 25, nos. 5\&6, pp. 393-408.

Nelson, K.E. (1990) Family-Based Services for Juvenile Offenders, Children and Youth Services Review, vol. 12, no. 3, pp. 193-212.

Nelson, K.E. (1991) Populations and Outcomes in Five Family Preservation Programs. In Family Preservation Services: Research and Evaluation, edited by K. Wells and D. Biegel, Sage Publications, pp. 72-91.

Park, J.M. and Helton, J. (2010) Transitioning from Informal to Formal Substitute Care Following Maltreatment Investigation, Children and Youth Services Review, vol. 32, no. 7, July, pp. 998-1003.

Park, J.M., Solomon, P. and Mandell, D.S. (2007) Foster Care Placement Among Children Who Received Inpatient Psychiatric Care, Children and Youth Services Review, vol. 29, no. 7, July, pp. 933-940.

Pellegrin, A. and Wagner, W.G. (1990) Child Sexual Abuse: Factors Affecting Victim's Removal from Home, 
Child Abuse and Neglect, vol. 14, no. 1, pp. 53-60.

Phillips, M.H., Shyne, A.W., Sherman, E.A. and Harding, B.L. (1971) Factors Associated With Placement Decisions in Child Welfare, Child Welfare League of America.

Poertner, J., Bussey, M. and Fluke, J. (1999) How Safe Are Out-of-Home Placements? Children and Youth Services Review, vol. 21, no. 7, pp. 549-563.

Quinton, D. and Rutter, M. (1984) Parents with Children in Care - 1. Current Circumstances and Parenting, Journal of Child Psychology and Psychiatry, vol. 25, no. 4, April, pp. 211-229.

Rapp, C.A. (1982) Effect of the Availability of Family Support Services on Decisions About Child Placement, Social Work Research and Abstracts, vol. 18, no. 1, pp. 21-27.

Rhee, S., Chang, J., Weaver, D. and Wong, D. (2008) Child Maltreatment Among Immigrant Chinese Families: Characteristics and Patterns of Placement, Child Maltreatment, vol. 13, no. 3, August, pp. 269-279.

Rivaux, S.L., James, J., Wittenstrom, K., Baumann, D., Sheets, J., Henry, J. and Jeffries, V. (2008) The Intersection of Race, Poverty and Risk: Understanding the Decision to Provide Services to Clients and to Remove Children, Child Welfare, vol. 87, no. 2, Special Issue, pp. 151-168.

Rosenthal, J.A., Motz, J.K., Edmonson, D.A. and Groze, V. (1991) A Descriptive Study of Abuse and Neglect in Out-of-Home Placement, Child Abuse and Neglect, vol. 15, no. 3, pp. 249-260.

Rossi, P.H., Schuerman, J. and Budde, S. (1999) Understanding Decisions About Child Maltreatment, Evaluation Review, vol. 23, no. 6, December, pp. 579-598.

Runyan, D.K., Gould, C.L., Trost, D.C. and Loda, F.A. (1981) Determinants of Foster Care Placement for the Maltreated Child, American Journal of Public Health, vol. 71, no. 7, July, pp. 706-711.

Schuerman, J., Rossi, P.H. and Budde, S. (1999) Decisions on Placement and Family Preservation, Evaluation Review, vol. 23, no. 6, December, pp. 599-618.

Thieman, A.A. and Dail, P.W. (1992) Family Preservation Services: Problems of Measurement and Assessment of Risk, Family Relations, vol. 41, no. 2, April, pp. 186-191.

Thieman, A.A. and Dail, P.W. (1997) Predictors of Out-of-Home Placement in a Family Preservation Program: Are Welfare Recipients Particularly Vulnerable?, Policy Studies Journal, vol. 25, no. 1, March, pp. 124-139.

Tittle, G., Harris, G. and Poertner, J. (2000) Factors That Predict the Decision to Place a Child, University of Illinois at Urbana-Champaign, School of Social Work, Child and Family Research Center, Urbana.

Trocmé, N., Knoke, D. and Blackstock, C. (2004) Pathways to the Over-representation of Aboriginal Children in Canada's Child Welfare System, Social Service Review, vol. 78, no. 4, December, pp. 577-600.

Vinnerljung, B., Franzen, E., Gustafsson, B. and Johansson, I.M. (2008) Out-of-Home Care Among Immigrant Children in Sweden: A National Cohort Study, International Journal of Social Welfare, vol. 17, no. 4, October, pp. 301-311.

Wobie, K., Eyler, F.D., Garvan, C.W., Hou, W. and Behnke, M. (2004) Prenatal Cocaine Exposure: An Examination of Out-of-Home Placement During the First Year of Life, Journal of Drug Issues, vol. 34, no. 1, January, pp. 77-94.

Yuan, Y. and Struckman-Johnson, D. (1991) Placement Outcomes for Neglected Children with Prior Placements in Family Preservation Programs. In Family Preservation Services: Research and Evaluation, edited by K. Wells and D. Biegel, Sage Publications, pp. 92-118.

Zuravin, S.J. and DePanfilis, D. (1997) Factors Affecting Foster Care Placement of Children Receiving Child Protective Services, Social Work Research, vol. 21, no. 1, March, pp. 34-42.

Zuravin, S.J. and DePanfilis, D. (1999) Predictors of Child Protection Service Intake Decisions: Case Closure, Referral to Continuing Services, or Foster Care Placement. In The Foster Care Crisis: Translating Research into Policy and Practice, edited by P.A. Curtis, G. Dale and J.C. Kendall, The Nebraska Press, pp. 63-83. 


\section{Study}

Phillips et al (1971)

Runyan et al (1981)

Quinton et al (1984)

Jones (1985)

Katz et al (1986)

Bebbington et al (1988)

Bebbington et al (1989)

Dalgleish et al (1989)

Hunter et al (1990)

Pellegrin et al (1990)

Jaudes \& Morris (1990)

Nelson (1990) (a)

Nelson (1990) (b)

Nelson (1991) (a)

Nelson (1991) (b)

Yuan et al (1991) (a)

Yuan et al (1991) (b)

Lindsey (1991)

Lindsey (1992b)

Thieman \& Dail (1992)

Leifer et al (1993)

Thieman \& Dail (1997)

Zuravin et al (1997)

Needell \& Barth (1998)

Zuravin et al (1999)

Hestbæk (1999)

Tittle et al (2000)

McDonald et al (2001)

De Kemp et al (2003)

Needell et al (2003)

Lau et al (2003)

Leschied et al (2003)

Trocmé et al (2004)

Berger et al (2004)

Wobie et al (2004)

English et al (2005)

Hill (2005)

Goerge and Lee (2005)

Harris et al (2005) (a)

Harris et al (2005) (b)

41 Barth et al (2006b) (a)

\section{Location}

Eastern USA

N. Carolina, USA

London borough, UK

New York, USA

Boston, USA

England, UK

England, UK

Brisbane, Australia

N. Carolina, USA

A US county

Chicago, USA

Six US states

Six US states

Six US states

Six US states

California, USA

California, USA

USA

USA

Iowa, USA

USA

Iowa, USA

Large US city

California, USA

Baltimore, USA

Denmark

Illinois, USA

Illinois, USA

Netherlands

California, USA

San Diego, USA

Ontario, Canada

Canada

USA

Southern USA (cocaine)

Washington State, USA

USA

Illinois, USA

Illinois, USA

Illinois, USA

USA (urban)

\section{Differentiation}

Out-of-home care

Foster care

Out-of-home care

Foster care

Out-of-home care

Out-of-home care

Out-of-home care

Out-of-home care

Out-of-home care

Out-of-home care

Out-of-home care

Out-of-home care

Out-of-home care

Out-of-home care

Out-of-home care

Out-of-home care

Out-of-home care

Foster care

Out-of-home care

Out-of-home care

Foster care

Out-of-home care

Foster care

Foster care

Foster care

Out-of-home care

Foster care

Foster care

Out-of-home care

Foster care

Foster care

Out-of-home care

Out-of-home care

Out-of-home living

Out-of-home care

Out-of-home care

Out-of-home care

Out-of-home care

Out-of-home care

Out-of-home care

Out-of-home care
Service at home

Child maltreatment

General population

At risk of placement

Abused or neglected

General population

General population

Suspected child abuse

Sexual abuse

Sexual abuse

Sexual abuse

Delinquency

Status offence

Abused or neglected

Status offence

At risk of placement

At risk of placement

Service at home

At risk of placement

At risk of placement

Sexually abused black girls

Service at home

Child maltreatment

General population

Abused or neglected

General population

Abused or neglected

Abused or neglected

At risk of placement

Child maltreatment

Self-reported maltreatment

At risk of placement

Abused or neglected

General population

Control sample

At risk of placement

Abused or neglected

Entered AFDC-TANF

Abused or neglected

Abused or neglected

Child maltreatment

\begin{tabular}{|c|c|c|c|}
\hline \multicolumn{2}{|c|}{ No. of Children } & \multirow{2}{*}{ Technique } & \multirow{2}{*}{$\mathbf{R}^{2}$} \\
\hline $\mathbf{A}$ & B & & \\
\hline 71 & 238 & MLR & - \\
\hline 685 & 7,085 & LR & $17 \%$ \\
\hline 48 & 47 & DS & - \\
\hline 90 & 153 & MLR & $25 \%$ \\
\hline 38 & 147 & LLA & - \\
\hline 2,020 & 4,996 & LR & $32 \%$ \\
\hline 2,016 & 4,996 & LR & $33 \%$ \\
\hline 56 & 96 & MLR & $51 \%$ \\
\hline 50 & 50 & LR & $25 \%$ \\
\hline 18 & 25 & DA & - \\
\hline 55 & 83 & LR & - \\
\hline 97 & & DA & - \\
\hline 67 & & $\mathrm{DA}$ & - \\
\hline 96 & & DA & $29 \%$ \\
\hline 82 & & DA & $27 \%$ \\
\hline 229 & 1,347 & DA & $15 \%$ \\
\hline 123 & 479 & $\mathrm{DA}$ & $27 \%$ \\
\hline 350,812 & 466,498 & DA & - \\
\hline 9,507 & & OR & - \\
\hline $200 ?$ & $800 ?$ & DS & - \\
\hline 28 & 40 & LR & - \\
\hline 904 & 3,131 & LR & - \\
\hline 458 & 577 & LR & - \\
\hline 26,460 & 68,401 & LR & - \\
\hline 458 & 185 & LR & - \\
\hline 494 & $5.2 \mathrm{~m}$. & $\mathrm{CS}$ & - \\
\hline 190 & 203 & LR & - \\
\hline 2,886 & 3,866 & LR\&ANN & - \\
\hline 19 & 88 & ARS & - \\
\hline 29093 & 108,207 & LR & - \\
\hline 264 & 781 & LR & - \\
\hline 234 & 216 & DA & - \\
\hline 2891 & & LR & $28 \%$ \\
\hline 88504 & & MLR & - \\
\hline 66 & 220 & LR & - \\
\hline 1990 & & LR & $31 \%$ \\
\hline 2109 & & LR & $20 \%$ \\
\hline 644570 & & $\mathrm{HM}$ & - \\
\hline 2886 & 3,866 & LR & - \\
\hline 190 & 203 & LR & - \\
\hline 2,176 & & LR & $9 \%$ \\
\hline
\end{tabular}




$\begin{array}{ll}42 & \text { Barth et al (2006b) (b) } \\ 43 & \text { Davidson-Arad et al (2006) } \\ 44 & \text { Berger (2006) } \\ 45 & \text { Chang et al (2006) } \\ 46 & \text { Glisson et al (2006) } \\ 47 & \text { Knoke et al (2007) (a) } \\ 48 & \text { Knoke et al (2007) (b) } \\ 49 & \text { Park et al (2007) } \\ 50 & \text { Elmund et al (2007) } \\ 51 & \text { Franzen et al (2008) (a) } \\ 52 & \text { Franzen et al (2008) (b) } \\ 53 & \text { Franzen et al (2008) (c) } \\ 54 & \text { Farmer et al (2008) } \\ 55 & \text { Vinnerljung et al (2008) (a) } \\ 56 & \text { Vinnerljung et al (2008) (b) } \\ 57 & \text { Harpaz-Rotem et al (2008) } \\ 58 & \text { Rhee et al (2008) } \\ 59 & \text { Rivaux et al (2008) } \\ 60 & \text { Carter (2009) } \\ 61 & \text { Carter (2010) } \\ 62 & \text { Knott \& Donovan (2010) } \\ 63 & \text { Fluke et al (2010) } \\ 64 & \text { Hearn (2010) } \\ 65 & \text { Andersen et al (2010) (a) } \\ 66 & \text { Andersen et al (2010) (b) } \\ 67 & \text { Andersen (2010) } \\ 68 & \text { Damashek et al (2010) } \\ 69 & \text { Park et al (2010) } \\ 70 & \text { Horowitz et al (2011) } \\ 71 & \text { Ejrnæs et al (2011) (a) } \\ 72 & \text { Ejrnæs et al (2011) (b) } \\ 73 & \text { Ejrnæs et al (2011) (c) } \\ 74 & \text { Lavergne et al (2011) } \\ 75 & \text { Lightfoot et al (2011) } \\ & \end{array}$

USA (non-urban)
Central Israel
USA
Los Angeles (Koreans)
Tennessee, USA
Toronto, Canada (0-11)
Toronto, Canada (12-16)
Philadelphia, USA
Sweden (Foreign adoptees)
Sweden (0-6)
Sweden (7-12)
Sweden (13-17)
USA
Sweden (7-12)
Sweden (13-17)
10 US cities
Los Angeles (Chinese)
Texas, USA
USA (Indians)
USA (Indians)
USA
Canada
Richmond, USA
Denmark (0-6)
Denmark (13-17)
Denmark
Oklahoma, USA
USA
USA
Denmark (0-6)
Denmark (7-12)
Denmark (13-17)
Montreal, Canada
Minnesota, USA
Sis

Out-of-home care

Out-of-home care

Out-of-home living

Out-of-home care

Out-of-home care

Out-of-home care

Out-of-home care

Out-of-home care

Out-of-home care

Out-of-home care

Out-of-home care

Out-of-home care

Out-of-home care

Out-of-home care

Out-of-home care

Out-of-home care

Out-of-home care

Out-of-home care

Out-of-home care

Out-of-home care

Foster care

Out-of-home care

Out-of-home care

Out-of-home care

Out-of-home care

Out-of-home care

Out-of-home care

Out-of-home care

Out-of-home care

Out-of-home care

Out-of-home care

Out-of-home care

Out-of-home care

Out-of-home care
Child maltreatment

At risk of placement

General Population

Abused or neglected

Referred by the court

At risk of placement

At risk of placement

Mental health problems

General population

General population

General population

General population

Mental health problems

General population

General population

Exposed to violence

At risk of placement

Service at home

At risk of placement

At risk of placement

Child maltreatment

Child maltreatment

Service at home

General population

General population

General population

Sibling maltreatment death

Child maltreatment

Abused or neglected

General population

General population

General population

Substantiated maltreatment

Child maltreatment

$\begin{array}{llll}708 & & \text { LR } & 6 \% \\ 54 & 45 & \text { DA } & - \\ 28,143 & 234 & \text { PA } & 25 \% \\ 50 & 120 & \text { LR } & - \\ 1,019 & & \text { LR } & - \\ 297 & 2,715 & \text { LR } & - \\ 191 & 961 & \text { LR } & - \\ 500 ? & 1,390 ? & \text { SA } & - \\ 16522 & 1,026,523 & \text { LR } & - \\ 4968 & 546,779 & \text { LR } & - \\ 3485 & 549,377 & \text { LR } & - \\ 6386 & 457,229 & \text { LR } & - \\ 980 ? & 2,086 ? & \text { HM } & - \\ 3,717 & 554,169 & \text { LR } & - \\ 7,571 & 471,993 & \text { LR } & - \\ 88 & 587 & \text { LR } & - \\ 58 & 162 & \text { LR } & - \\ 6,352 & 9,635 & \text { LR } & - \\ 280 & & \text { LR } & - \\ 84 & 1,957 & \text { LR } & - \\ 14144 & 57658 & \text { LR } & 13 \% \\ 256 & 1,048 & \text { LR } & - \\ 11 & 40 & \text { DA } & - \\ 6,113 & 34,490 & \text { LR } & - \\ 31,490 & 25,885 & \text { LR } & - \\ 3,960 & 2,270,887 & \text { LR } & - \\ 168 & & \text { LR } & - \\ 3,038 & & \text { LR } & - \\ 294 ? & 2,854 ? & \text { LR } & - \\ 2,897 & 2,220,611 & \text { LR } & - \\ 1,884 & 1,884,942 & \text { LR } & - \\ 8094 & 1329678 & \text { LR } & - \\ 449 & & \text { LR } & 18 \% \\ 854 & 3,128 & \text { LR } & - \\ & & \end{array}$

\section{Table 1: Summary of Empirical Studies of the Placement Decision}

LR $=$ Logistic Regression, DA = Discriminant Analysis, DS = Descriptive Statistics, ANN = Artificial Neural Network, MLR $=$ Multiple Linear Regression, $\mathrm{PA}=$ Probit Analysis, LLA = Log Linear Analysis, $\mathrm{HM}=$ Hazard Model, $\mathrm{SA}=$ Survival Analysis, ARS = Aggregate Risk Scores, OR $=$ Odds Ratios, $\mathrm{CS}=\mathrm{Chi}$ Squared. 